\title{
Arnold Kirsch and mathematics education
}

\author{
Werner Blum
}

Accepted: 4 July 2014/Published online: 23 July 2014

(C) FIZ Karlsruhe 2014

\begin{abstract}
This article pays tribute to the German mathematics educator Arnold Kirsch (1922-2013), especially for his contributions to calculus education. The main aim of his work was to make mathematics accessible to learners so that they are able to genuinely understand the subject.
\end{abstract}

Arnold Kirsch (*Jan. 13, 1922, †Oct. 14, 2013), the author of the article on the fundamental theorem of calculus reprinted in this issue of $Z D M$, was one of the most famous German mathematics educators ever. He has substantially influenced the German-speaking discussion on mathematics teaching and learning as well as the practice of mathematics teaching in schools. A look into secondary level textbooks in Germany reveals traces of Kirsch's work in many places, from the introduction of fractions and whole numbers through the treatment of elementary functions up to the orchestration of differential and integral calculus.

Arnold Kirsch studied mathematics and physics in Göttingen and in Bern where he received his Ph.D. in mathematics under the supervision of H. Hadwiger. Until 1963 he was a high school teacher in Soltau and in Göttingen, and then for 3 years was a lecturer at the University of Gießen. From 1966 to 1971 Kirsch held a professorship of mathematics education at the Pedagogical University of Göttingen, and then until his retirement in 1987 a

This commentary paper refers to the article "The fundamental theorem of calculus: visually?" by A. Kirsch available at doi:10.1007/ s11858-014-0608-9. “

W. Blum ( $\square)$

University of Kassel, Kassel, Germany

e-mail: blum@mathematik.uni-kassel.de professorship of mathematics education at the newly founded University of Kassel.

Among Kirsch's most important contributions are subtle subject matter analyses (in German: "didaktische Sachanalysen") of nearly all mathematical topic areas. Together with his colleague Heinz Griesel he established in the seventies the so-called "Kassel school of mathematics education". His main goal was always to make mathematics accessible for learners so that they are able to genuinely understand the subject, as indicated by the title of his most important book, Mathematik wirklich verstehen (Kirsch 1994). In his work he also addressed general didactical aspects, such as relations of mathematics to the real world (applications and modelling; see Kirsch 1995b), proofs and proving (see Kirsch 1979a; Blum and Kirsch 1991), and aspects of simplification, the topic of his plenary lecture at the 3rd International Congress on Mathematical Education (ICME-3) which took place in Karlsruhe 1976 (see Kirsch 1977). The main message of this lecture characterizes his work: "simplification without falsification", that is, topics ought to be simplified in order to become more easily accessible for learners, but this simplification must not create an epistemological or subjectrelated barrier for further concept development.

Arnold Kirsch was an enthusiastic teacher, both at school and at university. His main goal was to enable students to deeply understand mathematics. His lectures were of a brilliant clarity, and his strong engagement with his mission, namely to make mathematics accessible for learners, always impressed his audience. He contributed to the secondary school mathematics textbook series Mathematik heute for more than 30 years. Most of his didactical inventions can be found in his textbook chapters, many of which were later adapted by other textbooks. Prominent examples are the treatment of proportional and inverse 
proportional functions (including the so-called rule-ofthree, "Dreisatz") in grade 7 (Kirsch 1969), of real numbers (Kirsch 1966), of exponential functions (Kirsch 1976), and of integral calculus (see below).

$\mathrm{He}$ was an editor of several scientific journals and books, and served as a member of advisory boards of several institutions and journals including the Institute for the Didactics of Mathematics in Bielefeld (IDM), the Journal für Mathematik-Didaktik (JMD), and the Zentralblatt für Didaktik der Mathematik (now published by Springer as ZDM-The International Journal on Mathematics Education). In 2011 he became an honorary member of the Gesellschaft für Didaktik der Mathematik (GDM), the scientific community of mathematics education in the German-speaking area.

A substantial part of Kirsch's work was always devoted to the teaching of differential and integral calculus. The aim was to elaborate the most important basic ideas ("Grundvorstellungen") for the crucial concepts of limit, derivative, and integral and to make them accessible as naturally as possible. Kirsch emphasized the meaning of a derivative as a rate of change and the meaning of an integral as a "generalized product", while the geometric concepts of a slope of the tangent line and an area serve as universal visualizations. According to Kirsch, learners ought to acquire both appropriate basic ideas and appropriate geometric representations. Among Kirsch's work is a mathematics paper with a geometric characterization of differentiability (Kirsch 1960), an idea which later led to the idea of a function microscope as an instrument to represent the concept of derivative visually and to distinguish between differentiable and non-differentiable functions (see Kirsch 1979b, 1995a). He also emphasized the application of the idea of rate of change to geometric examples such as the derivation of the volume of a sphere related to its radius (Kirsch 1999). In integral calculus, Kirsch suggested an "intellectually honest" introduction in which the "area collection function" is the crucial concept. More generally, Kirsch made influential suggestions for a conception of calculus at the upper secondary level (see, e.g., Blum and Kirsch 1979).

An example of his brilliant subject matter analyses is the treatment of the fundamental theorem of calculus (see Kirsch 1996, the German original of the article reprinted in this issue). By combining the basic ideas and geometric representations of derivative and integral, the fundamental theorem arises in an almost natural and self-evident way, unlike the usual treatment where only the familiar geometric representations are used (resulting often in students' statements such as "I can't understand at all why the slope of the tangent line and the area under the graph should be related in any way"). In this article, the focus is on the first part of the fundamental theorem of calculus ("The derivative at $x$ of the integral function of $f$ is $f(x)$ "). How also the second part of the fundamental theorem ("The integral from $a$ to $x$ over the derivative of $f$ is $f(x)-f(a)$ ") can be proved pre-formally, and why this part should be, unlike the usual order, the first part of this theorem, is elaborated in Blum and Kirsch (1996).

Arnold Kirsch's friends and colleagues well remember the inspiring talks and discussions with him, his enthusiasm for mathematics, his sensibility for learning and learners as well as his genuine modesty. The mathematics education community will commemorate him with affection and gratitude.

\section{References}

Blum, W., \& Kirsch, A. (1979). Zur Konzeption des Analysisunterrichts in Grundkursen. Der Mathematikunterricht, 25(3), 6-24.

Blum, W., \& Kirsch, A. (1991). Preformal proving: examples and reflections. Educational Studies in Mathematics, 22, 183-203.

Blum, W., \& Kirsch, A. (1996). Die beiden Hauptsätze der Differential- und Integralrechnung. Mathematik Lehren, 78, $60-65$.

Kirsch, A. (1960). Eine geometrische Charakterisierung der „Differenzierbarkeit" einer Funktion. Mathematisch-Physikalische Semesterberichte, 7, 96-110.

Kirsch, A. (1966). Zur Behandlung der reellen Zahlen im Oberstufenunterricht. In H. Schröder (Ed.), Der Mathematikunterricht im Gymnasium (pp. 215-227). Hannover: Schroedel.

Kirsch, A. (1969). An analysis of commercial arithmetic. Educational Studies in Mathematics, 1, 300-311.

Kirsch, A. (1976). Vorschläge zur Behandlung von Wachstumsprozessen und Exponentialfunktionen im Mittelstufenunterricht. Didaktik der Mathematik, 4, 257-284.

Kirsch, A. (1977). Aspects of simplification in mathematics teaching. In H. Athen \& H. Kunle (Eds.), Proceedings of the Third International Congress on Mathematical Education, Karlsruhe 1976 (pp. 98-119). Karlsruhe: FIZ.

Kirsch, A. (1979a). Beispiele für „prämathematische“ Beweise. In W. Dörfler \& R. Fischer (Eds.), Beweisen im Mathematikunterricht (Schriftenreihe Didaktik der Mathematik Band 2) (pp. 261-274). Wien: Hölder-Pichler-Tempsky.

Kirsch, A. (1979b). Ein Vorschlag zur visuellen Vermittlung einer Grundvorstellung vom Ableitungsbegriff. Der Mathematikunterricht, 25(3), 25-41.

Kirsch, A. (1994). Mathematik wirklich verstehen. Eine Einführung in ihre Grundbegriffe und Denkweisen (2nd ed.). Köln: Aulis.

Kirsch, A. (1995a). Pathologische Funktionen unter dem „Funktionenmikroskop“. Didaktik der Mathematik, 23, 18-28.

Kirsch, A. (1995b). „Verstehen des Verstehbaren“-auch im anwendungsorientierten Mathematikunterricht. Didaktik der Mathematik, 23, 250-264.

Kirsch, A. (1996). Der Hauptsatz-anschaulich? Mathematik Lehren, $78,55-59$.

Kirsch, A. (1999). Die Ableitung des Kugelvolumens: Verstehen und Verallgemeinern. In C. Selter \& G. Walther (Eds), Mathematikdidaktik als design science. Festschrift für Erich Christian Wittmann (pp. 120-127). Leipzig: Ernst Klett Grundschulverlag. 